\title{
Comparative Advantage and Market Distortions: A Policy Analysis Matrix for Iraqi Wheat Crop Production
}

\author{
Ammar Saad ${ }^{1}$, Zhang Rui Tao ${ }^{1} \&$ Xia Ying ${ }^{1,2}$ \\ ${ }^{1}$ Chinese Academy of Agriculture Scineces, Beijing, China \\ ${ }^{2}$ Basic Business Expenses of the Chinese Academy of Agricultural Sciences, Research on Agricultural Quality \\ and Green Development, Beijing, China \\ Correspondence: Xia Ying, Chinese Academy of Agriculture Scineces, Beijing, China. E-mail: xiaying@caas.cn
}

Received: July 30, 2018

doi:10.5539/jas.v11n2p82

\begin{abstract}
Wheat is the most crop have been subsidized by the government in Iraq, through subsidizing the input of the production (seed, pesticide, and machines), as well as, subsidize the output of the production through purchasing it from the producers at a high price compared to the world market price. The study aims to assess the competitive advantage of wheat production in Iraq through some of the measures derived from the policy analysis matrix. This study according to secondary data has published by Iraqi Ministry of Planning/Central Organization of Statistics and Information Technology 2018, for wheat production costs of cultivation season in Iraqi provinces 2017. The results of the study indicated that the coefficients measures show, there is a government subsidy for wheat output and that means, producers receive prices higher than international prices with the existence of this policy. While the comparative advantage indicators showed, the wheat crop in Iraq was achieved private profits due to government intervention in the inputs and outputs of production, nor competitive advantage in social prices. Where the policy reflection indexes/market distortions analysis shows, that the government policy for wheat production 2017 subsidized the producers on the consumer cost, where the local market price for wheat is higher than the price of wheat in the world market.
\end{abstract}

Keywords: policy analysis matrix, wheat crop production, Iraqi governorates

\section{Introduction}

\subsection{Background}

Wheat is one of the most important crops, which occupies an important economic position in many countries because it contains many nutrients, especially the carbohydrates. It is a strategic feature in the international economic relations, and most developing countries, including Iraq, are trying to reach self-sufficiency and thereby ensure national food security. Iraq has followed the policy of subsidizing the price of various forms to reach rapid growth rates of agricultural development by adopting a horizontal and vertical expansion in crop cultivation (Mohammed \& Mudhi, 2016).

Wheat is the first crop in Iraq in terms of government subsidy. The government provides various kinds of subsidies for wheat production and markets, such as subsidies on production inputs through subsidies on seed prices, pesticides, land, pumps and agricultural machinery, and low-interest loans. And subsidy production outputs through buying the wheat from wheat producers at prices higher than the international prices, where the reference of Iraqi Ministry of Planning through (the report of wheat production costs for the winter season of 2017 ) that the purchase of one ton with an average price of 507,000 Iraqi dinars equivalent 426 USD. Despite all government subsidies for the wheat crop, crop production cost is high and provides only a small profit margin and is a disincentive to domestic production of wheat.

The general index of local production of the wheat crop is not enough to cover $50 \%$ of domestic consumption (United State Department of Agriculture, 2017), which is a clear imbalance in the structure of economic policy in general and agricultural policy in particular.

Hence, the need for interest in this issue has been examined by studying the impact of price policy on wheat production through its effects on resource efficiency using a policy analysis matrix for this important strategic crop. That social prices lead to optimal utilization of resources and maximize production and benefit. Because it 
is about the impact of price policy, policymakers need to know the level of market distortions created by the price policy used as production inputs subsidy or subsidy for wheat output. Therefore, there is a need to evaluate these policies and measure the efficiency and comparative advantage of the wheat crop because of state intervention. The production of agricultural commodities in Iraq faces distortions in their markets as a result of the State intervention in the prices of production inputs and the price of output. Therefore, production is not often efficient, including wheat production, which may discourage production and producers if the world market price is lower than the social price (Mudhi, 2012)

The objectives of the current study are to measure and evaluate the profitability and the effects of direct and indirect the subsidize on wheat production in Iraq compared to the world market price. This article uses the Policy Analysis Matrix (PAM) to measure and evaluate the economic efficiency of the production systems of Iraq, measuring prices and private and social costs.

The Policy Analysis Matrix has been widely applied to calculate market-driven and social profits for many varieties of farming systems under several technological and institutional scenarios. That's showing the important additional insights could be obtained if the efficiency of farmers behavior is considered, as well as their observed behavior (Kanaka, 2013).

\subsection{Current Situations of Wheat Production in Iraq}

There is no any actual improvement of wheat crop yield for last ten years in Iraq, where the productivity is around 2 tons/ha that reflects the low technology and lack of development of wheat production in Iraq. Although there is a relative increase in production amount around $14.5 \%$ growth rate for the last ten years, where it was around 2 million tons in 2009 increased to 4 million ton in 2018, but this increase in production reflects the increase in harvested area of the crop, where it was around 1.2 million ha in 2009 and increased to 2.3 million ha in 2018, which resulted from the subsidized policy of inputs and output of the crop, that encourage farmers to adopt crop cultivation.

This relative increase in the amount of production does not meet the actual need for domestic consumption increase resulted from population growth, and this is conducive to increase the quantities imported from abroad to full fill the gap between the production and domestic consumption, which is costing the Iraqi economy large amounts of foreign currency. Production of Iraq wheat crop 2018 only covered 53\% of the actual consumption of 7.5 million tons, with the amount of import is 3.6 million tons (USDA, 2018). This is the case for the last 10 years (2009-2018).

So it is necessary to look at the wheat production policy and analyze it to find out the comparative advantage of wheat production in Iraq in general and determine the comparative advantage on the level of provinces in Iraq to determine economic policies are designed to plan the production, import, and export operations in order to achieve the efficiency of available production resources according to the agricultural policy matrix analytical method to determine the efficiency of the local production of the crop compared to global production.

\section{Methodology and Materials}

\subsection{Policy Matrix Analysis}

Quantitative analysis was followed through the use of the policy analysis matrix to derive some indicators and criteria to measure the impact of government price policy on wheat production in all Iraqi wheat producer provinces in winter season 2017. The study was based on data published by the Iraqi Ministry of Planning/Central Organization of Statistics and Information Technology 2018.

That the policy analysis matrix is a quantitative mathematical analytical method and a tool used to analyze comparative advantage by measuring the impact of government intervention policies and market distortions on the vertical commodity system or commodity chains from farm to final consumption and export point. The policy analysis matrix is defined as a mathematical framework that helps divide the commodity system into its basic components, namely, private profitability estimated at private prices, where the private prices is the price in world marked, social profitability estimated at social prices, where the social price is the price in Iraqi marked (local market price), and the difference between the two measures of profitability. The policy analysis matrix is specifically designed to analyze market distortions and price policy interventions and their impact on the commodity system.

Where inputs are divided into non-tradable inputs that are not internationally traded, such as services and land where the demander and the producer must be in the same location (Jenkins, Kuo, \& Harberger, 2011), and tradable inputs that are internationally traded, such as seed, fertilizer, pesticide, etc. 
The work of the Agricultural Policy Analysis Matrix involves to find out several important indicators of protection and comparative advantage. Agricultural Policy Analysis Matrix is the product of two cases of accounting, the first case known as profit which is the difference between revenue and costs, measured either in private or social terms. The second case measures the effects of distortions policies or market failures such as the difference between private values and social values as shown in table 1, by the divergence in the agricultural policy analysis matrix. These differences are approximate because social values are evaluated at the initial distorted levels of outputs and inputs. Thus, the Agricultural Policy Analysis Matrix provides guidance for gradual changes instead of wholesale ones (Monke \& Pearson, 1989).

Table 1. Policy analysis matrix

\begin{tabular}{|c|c|c|c|c|}
\hline & \multirow{2}{*}{ Revenue } & \multicolumn{2}{|c|}{ Costs } & \multirow{2}{*}{ Profit } \\
\hline & & Tradable inputs & Non-tradable inputs & \\
\hline Private prices & A & B & $\mathrm{C}$ & $\mathrm{D}^{1}$ \\
\hline Social prices & $\mathrm{E}$ & $\mathrm{F}$ & G & $\mathrm{H}^{2}$ \\
\hline Divergences & $\mathrm{I}^{3}$ & $\mathrm{~J}^{4}$ & $\mathrm{~K}^{5}$ & $\mathrm{~L}^{6}$ \\
\hline
\end{tabular}

Note. ${ }^{1}$ : Private profitability $(\mathrm{D})=\mathrm{A}-(\mathrm{B}+\mathrm{C}){ }^{2}:$ : Social profitability $(\mathrm{H})=\mathrm{E}-(\mathrm{F}+\mathrm{G}) ;{ }^{3}$ : Output transfer $(\mathrm{I})=\mathrm{A}$ $-\mathrm{E} ;{ }^{4}$ : Input transfer $(\mathrm{J})=\mathrm{B}-\mathrm{F} ;{ }^{5}$ : Factor transfer $(\mathrm{K})=\mathrm{C}-\mathrm{G} ;{ }^{6}$ : Net policy transfer $(\mathrm{L})=\mathrm{D}-\mathrm{H}$.

Source: Based on Monke and Pearson (1989).

The values in the first row calculate private profitability or financial profitability FP (D), which is the differences between private revenues $(\mathrm{A})$ and private costs $(\mathrm{B}+\mathrm{C})$ values at actual market prices. Measures $\mathrm{A}, \mathrm{B}, \mathrm{C}$, and D show taxes and transfers, they show the competitive ability of the agricultural system according to available technologies, output values, input costs, and policy transfers.

The second row of policy analysis matrix table provides social profitability SP $(\mathrm{H})$ measured at social prices, which is the differences between social revenues (E) and social values costs $(F+G)$. Effective results are achieved when the economy along its private prices for references to social prices. Social profits measure efficiency gains and provide a measure of comparative advantages (Cheng \& Beghin, 1999).

There are three coefficients used for comparisons between policy incentives and agricultural commodities. The nominal protection coefficient NPC is referring to the level of protection of the main product and if the NPC is larger than 1, the system takes advantage of the protection and if less than 1 the system is subject to taxes, where it is the ratio of the revenue in the private prices (A) compared to the revenue of the social prices (E). The EPC is Refers to the overall level of protection, taking into account the impact of policies on the value of tradable products and tradable inputs, where it is the ratio of value added in private prices (A - B) to value added in social prices (E - F) (Mamza, Salman, \& Adeoye, 2014). Profitability coefficient PC is measure policy reflection on the profitability of the system. If greater than 1 , the system benefits from net transfers from the sector, but if it is smaller than 1, the economy benefits from net transfers from the system, where it is the ratio of the profit in the private prices (D) compared to the profit of the social prices (H) (Pearson, Gotsch, \& Bahri 2003).

There are three indicators used for comparisons of the relative efficiency or comparative advantage among to agricultural commodities. The first indicator is the domestic resource cost DRC if the DRC is smaller than 1, the system has a comparative advantage which means that we use local resources of lower value than global resources. If the DRC is greater than 1, the system does not have a comparative advantage and social profitability is negative. Where it is the ratio of the non-tradable inputs in the social prices $(\mathrm{G})$ compared to $t$ value added in social prices $(\mathrm{E}-\mathrm{F})$.

Another indicator of the system's comparative advantage. It takes into account the full cost of production of the social prices $(F+G)$, which is more appropriate for the relative position of the different systems when they have different cost structure (tradable and non-tradable) because the DRC is biased in favor of the system containing on a larger scale of tradable inputs, where the SCB calculated dividing the total costs in the social prices on the revenues of the social prices $(F+G) / E$.

Financial cost-benefit (FCB) is a competitive system index, if FCB is smaller than 1, the system is competitive, and if it is greater than 1 , the system is not competitive and the financial profitability is negative, where it is the ratio of Non-tradable inputs $(\mathrm{C})$ to value added in private prices $(\mathrm{A}-\mathrm{B})$. 
Tow indicators used to measure the policy reflection index/Market distortions increase or decrease total system revenues. Producers subsidy ratio PSR is policy reflection index/market distortions to increase or decrease the total revenue of the system at social prices, which, the size of the difference from the reference situation at social prices to the current situation at market prices, it is calculated by divided Net policy transfer (L) on revenue in social prices $(\mathrm{E})$.

The second indicator is product subsidy equivalent PSE, it is defined the policy reflection index/market distortions to increase or decrease the total revenue of the system at market prices, where if it is positive indicate the policy subsidize the product and if it is negative the policy subsidize the consumer, it is calculated by divided Net policy transfer (L) on revenue in private prices (A) (Adeoye, Iyabo, \& Omobowale, 2013).

\subsection{Data Collection and Calculations.}

The assessment of the elements of the policy analysis matrix in the USD needs to know the exchange rate of the local currency against the USD because the matrix data from the revenues and costs are valued at local private prices, which are market prices, which contain distortions and market failures, and must be corrected according to social prices.

Social assessment and efficiency analysis in accordance with commodity regulations is based on international prices, which are denominated in foreign currencies. Therefore, it is necessary to know the exchange rate, which is necessary to estimate international prices.

Where the exchange rate was adopted in this study 1190 Iraqi dinars against the 1 USD, according to the bulletin of the Central Bank of Iraq.

The prices of the Policy matrix analysis have been calculated based on the secondary data published by Ministry of Planning/Central Organization for Statistics and Information Technology 2018 (report of the cost and Production survey and Disposal of wheat crops for the Winter Season 2017)

The data of current situations (harvested areas, production, yield, domestic consumption, and import) have been collected from the official website of United State Department of Agriculture (USDA) 2018.

\section{Result and Discussion}

\subsection{Policy Matrix Analysis}

After calculating the production inputs costs and revenues at private and social prices, we can build components estimates of policy analysis matrix by filling the rows and columns of the sample.

The matrix was built on the basis of the production of one hectare and on the governorates level, and the total sample USD/ha of the wheat crop, Table 2 shows the results of the policy analysis matrix for the production of one hectare of wheat in Iraq 2017 on governorates level.

The results of the matrix indicate that the wheat crop in Iraq is profits earned to the producers in the private prices, where D values were Positive at every governorate and the total sample.

While the wheat crop in Kirkuk, Al-Najaf, and Maysan provinces achieves positive social profitability (H), but it is much lower than private profitability, namely the system in these provinces are able to survive without assistance from the government. This indicates the efficiently use of non-tradable inputs (local resources) but not optimally, which requires to increase the productivity or reduced production costs through the use of resources more efficient in these provinces by introducing modern technologies patterns and redistributing resources more efficiently. This indicates that the price policy encourages for use of local resources but in low efficiency. While the social profitability $(\mathrm{H})$ in the remaining provinces and total sample in this study were negative, this indicates the waste use of non-tradable inputs (local resources), which requires to encourage for efficient use of resources in these provinces by introducing modern technologies.

The results also show that the divergences revenues (I) were positive in all the governorate matrices and the total sample of the study, which are the results of the difference between the private prices revenues (A) and the social prices revenues $(\mathrm{E})$. This means that the private revenues are greater than the social revenues of all the matrices, which indicates the high government intervention for wheat production 2017, resulted from the government intervention through buying the wheat production from producers at high prices (higher than the world production price) and market failures that shown from divergences of tradable inputs $(\mathrm{J})$, where the results of the matrix for all the governorates and the total sample indicated that they were all negative, which means that the tradable inputs in social prices are higher than tradable inputs in private prices, which indicates a high subsidy on tradable inputs. As well as the market failures, have shown from divergences of non-tradable inputs (K) in eleven governorates (Maysan, Thi-Qar, Al-Muthanna, Al-Qadisiya, Al-Najaf, Wasit, Karbala, Babylon, Baghdad, Diyala, 
Kirkuk) and the total sample indicated that they were all negative, which means that the non-tradable inputs in social prices are higher than non-tradable inputs in private prices, which indicates a high subsidy on non-tradable inputs, but in Basra province non-tradable inputs $(\mathrm{K})$ was positive which indicates for unsubsidized non-tradable inputs.

The positive value of the net effect (L) resulted in policy matrix analyses Table 2 for every province and the total sample of the study indicates that wheat production 2017 in Iraq is more profitable for producers with market distortions than the profitability without market distortions. Government intervention policies in the wheat commodity system reflected on the prices of tradable and non-tradable inputs and output prices, which are entirely for benefit of domestic producers for short-term (Mohammed \& Mudhi, 2015).

Table 2. The results of the policy analysis matrix for the production of one hectare of wheat in Iraq in 2017

\begin{tabular}{|c|c|c|c|c|c|}
\hline \multirow{2}{*}{ Governorates } & & \multirow{2}{*}{ Revenue } & \multicolumn{2}{|c|}{ Costs } & \multirow{2}{*}{ Profit } \\
\hline & & & Tradable inputs & Non-tradable inputs & \\
\hline \multirow{3}{*}{ Kirkuk } & Private prices & 1147.90 & 100.67 & 322.99 & 724.24 \\
\hline & Social prices & 722.59 & 122.09 & 518.08 & 82.42 \\
\hline & Divergences & 425.30 & -21.42 & -195.09 & 641.82 \\
\hline \multirow{3}{*}{ Diala } & Private prices & 1120.34 & 224.27 & 420.71 & 475.36 \\
\hline & Social prices & 794.52 & 276.78 & 575.60 & -57.85 \\
\hline & Divergences & 325.81 & -52.51 & -154.89 & 533.21 \\
\hline \multirow{3}{*}{ Baghdad } & Private prices & 1120.34 & 192.47 & 348.61 & 579.26 \\
\hline & Social prices & 794.52 & 225.62 & 894.15 & -325.25 \\
\hline & Divergences & 325.81 & -33.15 & -545.55 & 904.51 \\
\hline \multirow{3}{*}{ Babylon } & Private prices & 1601.34 & 263.06 & 436.54 & 901.75 \\
\hline & Social prices & 941.03 & 315.29 & 735.53 & -109.80 \\
\hline & Divergences & 660.32 & -52.24 & -298.99 & 1011.55 \\
\hline \multirow{3}{*}{ Karbala } & Private prices & 1525.04 & 158.25 & 479.50 & 887.29 \\
\hline & Social prices & 863.48 & 180.34 & 775.60 & -92.45 \\
\hline & Divergences & 661.56 & -22.08 & -296.10 & 979.75 \\
\hline \multirow{3}{*}{ Wasit } & Private prices & 1411.43 & 189.11 & 402.76 & 819.56 \\
\hline & Social prices & 833.85 & 226.88 & 635.36 & -28.39 \\
\hline & Divergences & 577.58 & -37.77 & -232.61 & 847.96 \\
\hline \multirow{3}{*}{ Al-Najaf } & Private prices & 1528.07 & 219.46 & 385.71 & 922.89 \\
\hline & Social prices & 887.93 & 256.97 & 627.19 & 3.76 \\
\hline & Divergences & 640.14 & -37.51 & -241.48 & 919.13 \\
\hline \multirow{3}{*}{ Al-Qadisiya } & Private prices & 1093.45 & 194.76 & 331.46 & 567.23 \\
\hline & Social prices & 682.50 & 241.04 & 529.68 & -88.22 \\
\hline & Divergences & 410.95 & -46.29 & -198.22 & 655.45 \\
\hline \multirow{3}{*}{ Al-Muthnna } & Private prices & 694.79 & 95.33 & 339.60 & 259.87 \\
\hline & Social prices & 484.89 & 116.91 & 435.23 & -67.25 \\
\hline & Divergences & 209.90 & -21.58 & -95.63 & 327.11 \\
\hline \multirow{3}{*}{ Thi Qar } & Private prices & 998.99 & 178.52 & 350.42 & 470.05 \\
\hline & Social prices & 652.65 & 209.90 & 655.13 & -212.37 \\
\hline & Divergences & 346.34 & -31.38 & -304.71 & 682.42 \\
\hline \multirow{3}{*}{ Maysan } & Private prices & 1374.79 & 194.76 & 290.55 & 889.48 \\
\hline & Social prices & 800.69 & 238.18 & 416.77 & 145.74 \\
\hline & Divergences & 574.10 & -43.42 & -126.22 & 743.74 \\
\hline \multirow{3}{*}{ Al-Basra } & Private prices & 757.31 & 213.68 & 476.74 & 66.89 \\
\hline & Social prices & 482.02 & 250.31 & 474.72 & -243.01 \\
\hline & Divergences & 275.29 & -36.63 & 2.02 & 309.90 \\
\hline \multirow{3}{*}{ Total } & Private prices & 1271.26 & 196.64 & 390.62 & 684.00 \\
\hline & Social prices & 781.86 & 234.84 & 604.34 & -57.32 \\
\hline & Divergences & 489.40 & -38.20 & -213.71 & 741.32 \\
\hline
\end{tabular}




\subsection{Analyze Results}

Based on the estimates of the policy analysis matrix for wheat production in Iraq 2017, shown in Table 2 for the matrices of governorates and total sample. We can calculate the protection coefficients and comparative advantage measures, which are economic indicators that can measure the impact of government intervention on input and output prices and market failures, as well as the efficiency of the use of resources.

\subsubsection{The Coefficients Measure}

It is noted that the Nominal Protection Coefficient NPC of production was greater than 1 for every governorate and the total sample as shown in Table 3. This means that the price protected for wheat is greater than the world market price sold, for $163 \%$ for the total sample, which indicates that there is a government subsidy for wheat output and that means, producers receive prices higher than international prices with the existence of this policy.

This is called positive protection for producers. Conversely, consumers face negative protection and they have to pay higher prices for obtaining the wheat product by the existing government policy.

While the Effective Protection Coefficient EPC for every governorate and the total sample was positive and greater than 1, as shown in Table 3 (coefficients Indicators). This means that the added value of wheat production at private prices is greater than the value added at social prices by $196 \%$ for the total sample. Indicating a positive protection for wheat production in Iraq 2017 resulting from the purchase of wheat by the government at a price that is higher than the effect of customs duties on imports of tradable inputs. The combined effect of the differences between revenues and the costs of tradable inputs makes private profits higher than social profits, which also shows that the wheat market in Iraq is not fully competitive.

The Profitability Coefficient PC index values in every province and total sample shows that the private profits (D) were always greater than social profits $(\mathrm{H})$, this means that the wheat production system in Iraq does not benefit from the government subsidy policy to achieve high social profits compared to private profits.

\subsubsection{The Comparative Advantage Measure}

Domestic resources cost DRC values were smaller than 1 for (Kirkuk, Al-Najaf, and Maysan) governorates, that indicates, the system has a comparative advantage which means these provinces use local resources lower value than global resources. Where the other provinces and total sample DRC values were greater than 1 , namely the system has no comparative advantage which means using local resources higher value than global resources.

As well as the social costs benefit SCB, which is the other indicator of the system's comparative advantage. It takes into account the full cost of production of the social prices, confirmed the DRC finding, where SCB values for Kirkuk, Al-Najaf, and Maysan were positive, which means the system has a comparative advantage and efficient use of resources in these provinces. While SCB values for other provinces and a total sample of the study were negative, which means the system has no comparative advantage and the waste of resources use as shown in Table 3 (Comparative advantage Indicators).

On the other hand, Financial Costs Benefits FCB values were smaller than 1 for every governorate and total sample, as shown in Table 4. Which means the system is competitive in private prices, namely, the system generates private profits in Iraq.

\subsubsection{The Policy Reflection Index/Market Distortions}

The positive values of Product Subsidy Equivalent PSE for every governorate and total sample means the government policy subsidize producer on the consumer account, namely overall transfer to the producer from consumer.

The product subsidy rates PSR values were positive in every governorate and the total sample, indicated that there is a real support and positive incentives for domestic producers of the wheat crop in Iraq 2017 so that the ratio for the total sample was $95 \%$. These incentives are explained by the government purchase of the crop at a high price, average price $426 \mathrm{USD} /$ ton, and the consequent, rise in wheat prices in local markets. 
Table 3. Indicators of the policy analysis matrix

\begin{tabular}{|c|c|c|c|c|c|c|c|c|}
\hline \multirow[t]{2}{*}{ Governorates } & \multicolumn{3}{|c|}{ Coefficients Indicators } & \multicolumn{3}{|c|}{ Comparative advantage Indicators } & \multicolumn{2}{|c|}{$\begin{array}{l}\text { Indicators of policy reflection } \\
\text { index/market distortions }\end{array}$} \\
\hline & NPC & EPC & $\mathrm{PC}$ & DRC & FCB & $\mathrm{SCB}$ & PSE & PSR \\
\hline Kirkuk & 1.59 & 1.74 & 8.79 & 0.86 & 0.31 & 7.77 & 0.56 & 0.89 \\
\hline Diala & 1.41 & 1.73 & -8.22 & 1.11 & 0.47 & -14.73 & 0.48 & 0.67 \\
\hline Baghdad & 1.41 & 1.63 & -1.78 & 1.57 & 0.38 & -3.44 & 0.81 & 1.14 \\
\hline Babylon & 1.70 & 2.14 & -8.21 & 1.18 & 0.33 & -9.57 & 0.63 & 1.07 \\
\hline Karbala & 1.77 & 2.00 & -9.60 & 1.14 & 0.35 & -10.34 & 0.64 & 1.13 \\
\hline Wasit & 1.69 & 2.01 & -28.86 & 1.05 & 0.33 & -30.37 & 0.60 & 1.02 \\
\hline Al-Najaf & 1.72 & 2.07 & 245.19 & 0.99 & 0.29 & 234.90 & 0.60 & 1.04 \\
\hline Al-Qadisiya & 1.60 & 2.04 & 1.20 & 1.20 & 0.37 & -8.74 & 0.60 & 0.96 \\
\hline Al-Muthanna & 1.43 & 1.63 & -3.86 & 1.18 & 0.57 & -8.21 & 0.47 & 0.67 \\
\hline Thi-Qar & 1.53 & 1.85 & -2.21 & 1.48 & 0.43 & -4.07 & 0.68 & 1.05 \\
\hline Maysan & 1.72 & 2.10 & 6.10 & 0.74 & 0.25 & 4.49 & 0.54 & 0.93 \\
\hline Al-Basra & 1.57 & 2.35 & -0.28 & 2.05 & 0.88 & -2.98 & 0.41 & 0.64 \\
\hline Total & 1.63 & 1.96 & -11.93 & 1.10 & 0.36 & -14.64 & 0.58 & 0.95 \\
\hline
\end{tabular}

\section{Conclusions and Recommendations}

\subsection{Conclusions}

The results of agricultural policy analysis of the wheat crop producer governorates in Iraq 2017 showed that the crop generates private profits in every governorate and total sample in varying percentages. As for social profits, only three governorates (Kirkuk, Al-Najaf, and Maysan) achieved social profits but much lower than private profits. The rest of the governorates and total sample produced negative social profits.

The analysis of product protection indicators shows that the government subsidizes production inputs by providing inputs at lower prices than social prices. Production output is also subsidized by the government through purchasing the production at higher prices than world market prices, which explains the rise in private profits significantly for social profits.

The indicators of comparative advantage indicated that the wheat crop in Iraq is not characterized by the comparative advantage except in three governments (Kirkuk, Al-Najaf, and Maysan), despite the achievement of all the provinces for private profits. This indicates the inefficient use of resources in most governments through government intervention and market distortions of the product that discourages to optimize the use of resources.

\subsection{Recommendations}

Based on the findings of the research we can come up with some recommendations:

(1) Redistributing resources more efficiently and encourage farmers to make optimum use of resources.

(2) Adoption of modern farming methods such as the use of improved seeds and the adoption of modern irrigation methods to face water scarcity and to increase the productivity of wheat crop production.

(3) The government needs to take action at the level of foreign trade in order to protect the local product and improve the efficiency of agricultural systems for the wheat crop.

\section{References}

Adeoye, I., \& Oni, O. (2013). Policy Analysis and Competitiveness of Plantain Processing in Southwestern Nigeria. Journal of Sustainable Development in Africa, 15(7), 135-151.

Cheng, F., \& Beghin, J. C. (1999). Food Self-Sufficiency, Comparative Advantage, and Agricultural Trade: A Policy Analysis Matrix for Chinese Agriculture. CARD Working Paper (p. 29). Retrieved from http://works.bepress.com/john-beghin/24

Jenkins, G. P., Kuo, C.-Y., \& Arnold, C. H. (2011). Cost-Benefit Analysis for Investment Decisions. JDI Executive Programs.

Kanaka, S. (2013). The Policy Analysis Matrix of Rice Cultivation in India. European Journal of Physical and Agricultural Sciences, 1(1), 8-19. 
Mamza, A. O., Salman, K. K., \& Adeoye, I. B. (2014). Competitiveness of Beef Processing in Borno State of Nigeria: A Policy Analysis Matrix Approach. Journal of Agriculture and Sustainability, 6(2), 132-47.

Mohammed, N. J., \& Mudhi, A. A. (2015). Measuring of The Comparative Advantage and Competitiveness on Wheat Production in Iraq by Using Policy Analysis Matrix. Journal of Tikrit University for Agriculture Sciences, 15(3), 260-271.

Mohammed, N. J., \& Mudhi, A. A. (2016). Analyzing the Impact of the Price Policy on Wheat Production in Iraqby Using Policy Analysis Matrix (PAM). The Iraqi Journal of Agricultural Sciences, 2(47), 552-62.

Monke, E. A., \& Scott, R. P. (1989). The Policy Analysis Matrix for Agricultural Development. Business \& Economics (p. 279).

Mudhi, A. (2012). Policy Analysis Matrix for Barley Crop in the Northern Region of Iraq in 2005. Journal of Administration \& Economics, 91, 239-247.

Pearson, S., Carl, G., \& Sjaiful, B. (2003). Applications of the Policy Analysis Matrix in Indoneisan Agriculture. Jakarta: Yayasan Obor Indonesia.

USDA (United States Department of Agriculture). (2018). Retrieved from https://www.indexmundi.com/ agriculture/?country=iq\&commodity $=$ wheat $\&$ graph $=$ production

\section{Copyrights}

Copyright for this article is retained by the author(s), with first publication rights granted to the journal.

This is an open-access article distributed under the terms and conditions of the Creative Commons Attribution license (http://creativecommons.org/licenses/by/4.0/). 